\title{
Remitting Seronegative Symmetrical Synovitis with Pitting Edema (RS3PE) Syndrome: A Single-Center Experience
}

\section{Tekrarlayıcı Seronegatif Pitting Ödemli Simetrik Sinovit (R3SPE) Sendromu: Tek Merkez Deneyim}

\author{
DDilek Tezcan', @Semral Gülcemal', @Muhammet Limon², \Sema Yılmaz'
}

'Selçuk University, Faculty of Medicine, Division of Rheumatology, Konya, Turkey

${ }^{2}$ Kahramanmaraş City Hospital, Division of Rheumatology, Kahramanmaraş, Turkey

\begin{abstract}
Objective: Remitting seronegative symmetrical synovitis with pitting edema (RS3PE) is a rare disorder characterized by pitting edema, the onset of acute polyarthritis, and negative rheumatoid factor. The absence of joint erosion and good long-term response to low-dose steroids are its other characteristics. The present study aimed to evaluate the characteristics and accompanying conditions of RS3PE for contributing to the literature on the issue.
\end{abstract}

Material and Method: This is descriptive casebased retrospective study was carried out in a rheumatology clinic between January 2019- October 2020. Fifteen patients over 18 diagnosed with RS3PE were included in the study.

Results: Of 15 patients diagnosed with RS3PE, seven were female, and eight male. The following comorbid disorders were present: relapsing polychondritis, scleroderma, seropositive rheumatoid arthritis, gout, monoclonal gammopathy of unknown significance, and primary myelofibrosis. Most patients other than the ones who have hematological malignities and those diagnosed with relapsing polychondritis responded rapidly to steroids, and no recurrence occurred.

Conclusion: RS3PE may be associated with neoplasia, drugs, and various rheumatismal conditions, suggesting that it may be heterogeneous and considered a paraneoplastic rheumatic disease. The rare occurrence of this syndrome leads clinicians to miss it commonly. It is essential to increase awareness of this entity among clinicians.

Keywords: Comorbidities, paraneoplastic; arthritis; pitting edema, remitting seronegative symmetrical synovitis with pitting edema syndrome
Öz

Amaç: Tekrarlayıcı seronegatif pitting ödemli simetrik sinovit sendromu (R3SPE), akut poliartrit başlangıcı olan, negatif romatoid faktör ve pitting ödem ile karakterize nadir bir hastalıktır. Eklem erozyonu yapmaması ve düşük doz steroide iyi yanıt vermesi diğer özellikleridir. Bu çalışma, RSPE sendromu özelliklerini ve eşlik eden durumları değerlendirmeyi ve literature katkıda bulunmayı amaçlamaktadır.

Gereç ve Yöntem: Bu tanımlayıcı vaka bazlı retrospektif çalışma Romatoloji kliniğinde Ocak 2019- Ekim 2020 tarihleri arasında yapıldı. 18 yaş üstü on beş RS3PE hastası çalışmaya dahil edildi.

Bulgular: RS3PE tanısı konulan 15 hastanın yedisi kadın ve sekizi erkekti. Tekrarlayan polikondrit, skleroderma, seropozitif romatoid artrit, gut, önemi bilinmeyen monoklonal gamopati ve primer miyelofibroz komorbid bozuklukları mevcuttu. Hematolojik malignitesi olanlar ve tekrarlayan polikondrit tanısı konanlar dışındaki hastaların çoğu steroid tedavisine hızla yanıt verdi ve nüks gözlenmedi.

Sonuç: RS3PE sendromu, heterojen bir hastalıktır. Neoplazi, ilaçlar ve çeşitli romatizmal hastalıklar ile ilişkili olabilmekte ayrıca paraneoplastik romatizmal hastalik olabileceği düşünülmektedir. Bu sendrom nadir görülmesi nedeniyle klinisyenlerin gözünden kaçabilir ve bu yüzden klinisyenler arasında hastalık açısından farkındalığını arttırmak esastır.

Anahtar Kelimeler: Artrit; komorbiditeler; paraneoplastik; pitting ödem; tekrarlayıcı seronegatif pitting ödemli simetrik sinovit

Corresponding (IIletişim): Dilek Tezcan, Selcuk University School of Medicine Department of Internal Medicine, Division of Rheumatology, Konya, Turkey

E-mail (E-posta): dr_dilekturan@hotmail.com

Received (Geliș Tarihi): 08.07.2021Ａccepted (Kabul Tarihi): 07.09.2021 


\section{INTRODUCTION}

Remitting seronegative symmetrical synovitis with pitting edema (RS3PE) was initially described by Mc Carty et al. in 1985 as one of the subgroups of seronegative rheumatoid arthritis (RA). ${ }^{[1]}$ Subsequently, it has been suggested that it is a distinct clinical entity from RA. ${ }^{[2]}$ Although the prevalence of RS3PE is not entirely known, it is considered quite rare. Clinically, it frequently presents with acute, symmetrical, and polyarticular involvement. The most typical disease feature is marked pitting edema on dorsal aspects of hands and feet developing due to tenosynovitis. In all ten original cases described by McCarty the disease was bilaterally symmetrical. Since McCarty's original description over 150 cases of RS3PE has been reported. In almost all the cases it is described as a symmetrical disease involving both hands and rarely the feet .Thus symmetrical presentation is considered as one of the hallmark of disease. However exceptions are always there. RS3PE too presents in an asymmetrical and unilateral pattern, though it is extremely rare. Thus diagnosing it always poses a clinical challenge, and correct diagnosis is delayed often. ${ }^{[3]}$ The absence of specific diagnostic criteria and asymmetrical unilateral patterns makes the diagnosis of RS3PE more difficult. RS3PE may be associated with neoplasia and various rheumatismal conditions, suggesting that it may be heterogenous natüre. The present study aimed to evaluate the clinical, laboratory, and radiological characteristics of 15 cases given the literature.

\section{MATERIAL AND METHOD}

This is a descriptive casebased and retrospective study on RS3PE syndrome, which is a rare rheumatological disorder. This single-center study was carried out between January 2019 and October 2020 in Rheumatology Department. Retrospectively, 15 patients over the age of 18 who were clinically diagnosed with RS3PE syndrome were registered in this study. ${ }^{[4]}$ We excluded renal, liver, cardiovascular disease, elderly-onset rheumatoid arthritis, and polymyalgia rheumatica (PMR) based on clinical characteristics, imaging (radiological and ultrasound findings). Data on patients with RS3PE were reached by reviewing patient files and medical records. Age, sex, history, involvement type and site, the symptoms and comorbidities, probable etiological factors, laboratory findings, and treatment options were recorded. C-reactive protein (CRP), erythrocyte sedimentation rate (ESR) hemogram parameters were recorded to evaluate activation in patients. For screening probable accompanying malignity, mammography, abdominal and neck USG examination, and gynecological examination were carried out in women and men; in addition to neck and abdominal USG, prostate malignity was attempted to be ruled out. In patients suspected to have hematological malignities, hematology consultation was made. For differential diagnosis, extremity graphics, uric acid, rheumatological antibodies, antinuclear antibodies (ANA), Anti-cyclic citrullinated peptide antibody
(anti-CCP), and RF analysis were ordered. To eliminate the probable infection in suspected patients, procalcitonin, brucella test, urinalysis, and lung radiography were ordered. An echocardiography examination was ordered to exclude heart failure. Total protein and albumin evaluation, thyroid, kidney, and liver function tests, and proteinuria investigation in urine were carried out.

The present study was performed by following the principles of the Helsinki Declaration, and written informed consent was obtained from all participants. Patients gave their informed consent to be subjected to the protocol. Approval for the study was obtained from the ethics committee with the decision dated 22.04.2020 and numbered. 2020/181.

\section{Statistical Analysis}

All statistical analyses were performed with IBM SPSS 22.0 software. Demographic characteristics and laboratory findings of the patients were summarized using descriptive statistics. Numerical variables were expressed as mean \pm standard deviation (range: min-max) or median, and also categorical variables were described as counts ( $n$ ) and percentages (\%).

\section{RESULTS}

Of 15 patients diagnosed with RS3PE, seven were female, and eight male. The mean age of the patients was $65.53 \pm 14$ years (47-86); physical examination findings were as follows: arthritis in bilateral ankle three patients, in bilateral wrists in 5 patients, in the unilateral wrist and metacarpophalangeal joints in 2 patients, the unilateral ankle and metatarsophalangeal joints in 3 patients and asymmetrical wrist and ankle joints in 2 patients and pitting edema in the dorsum of hand or foot in all patients (shown in Figure 1, 2 and Table 1). In the radiological examination, no erosive changes were observed in joints. Mean value of CRP was found to be $68.5 \pm 61.6 \mathrm{mg} / \mathrm{dl}$ and ESR $58 \pm 20 \mathrm{~mm} / \mathrm{s}$. $\mathrm{RF}$, anti-CCP tests were negative except for one patient with the diagnosis of RA and, the ANA test was negative except for cases with relapsing polychondritis and scleroderma, respectively. No pathological findings were established in procalcitonin, brucella tests, total protein, albumin, thyroid, kidney, liver function tests, and urinalysis and proteinuria tests in the urine. Laboratory results are summarized in Table 2. Abdominal and pelvis ultrasonography demonstrated normal size and structure in the liver, spleen, and kidneys. No lymphadenopathy or malignity was found. There was no finding suggesting heart failure, and in lung radiography in the echocardiographic examination, no pathological findings such as infection and mass were observed. Two patients had no known systemic disease. In the Doppler USG examination carried out in patients with unilateral foot involvement, deep vein thrombosis was not found. As to accompanying rheumatological diseases, one had relapsing polychondritis, one scleroderma, one gout, and one seropositive rheumatoid arthritis. After screening for 
malignity, MGUS was detected in one patient and primary myelofibrosis in another, and the hematology department followed them. Five patients had hypertension, and three patients' diabetes mellitus. Of diabetes patients, one was on empagliflozin treatment as oral antidiabetic, and 2 received insulin treatment. Patients responded rapidly to steroids.

Recurrence occurred in two patients with hematological malignity and one with relapsing polychondritis. RP responded to methotrexate treatment, while MGUS and myelofibrosis cases went into remission with high dose steroid treatment. The rheumatology department is still following them up.

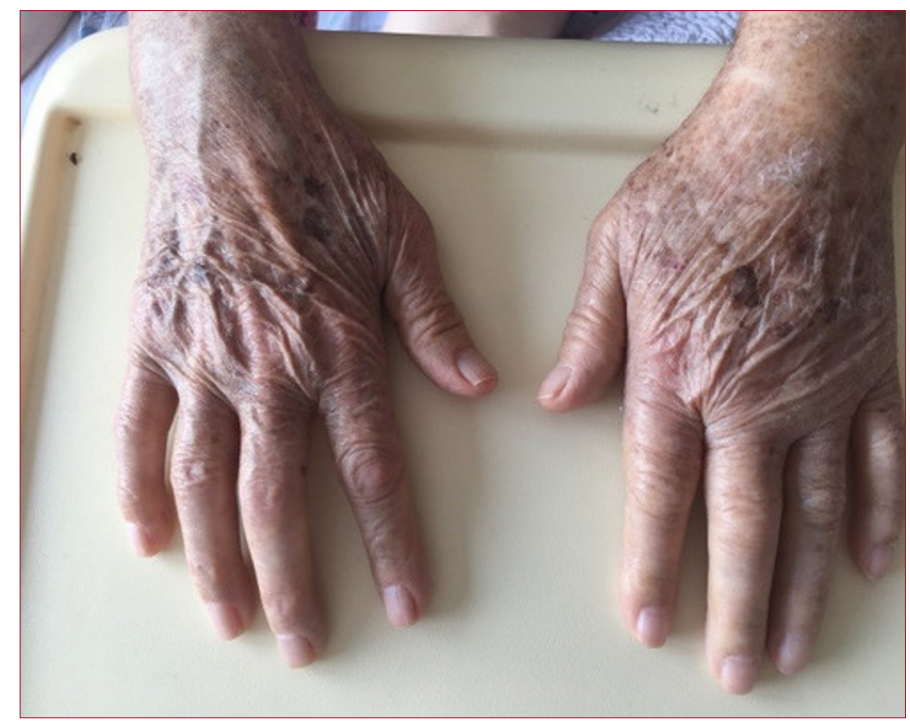

Figure 1. Clinical photograph of the patients showing pitting edema of the hands

\section{Table 2. RS3PE syndrome laboratory characteristics}

\section{Variables}

CRP(mg/L ) [0-8]

ESR (mm/hour) [0-20]

Leukocyte(10\%/L) [3.5-10.5]

Hemoglobin (g/dL) [12-15.5]

Platelet $\left(10^{9} / \mathrm{L}\right)[150-450]$

Neutrophil $\left(10^{9} / \mathrm{L}\right)[1.7-7]$

Lymphocyte $\left(10^{9} / \mathrm{L}\right)[0.9-2.9]$

Monocytes $\left(10^{9} / \mathrm{L}\right)[0.2-0.8]$ * Data were presented as mean \pm standard deviation (range: $\min -$ max) or median, and described as
counts(n); RS3PE syndrome- Remitting seronegative symmetrical synovitis with pitting edema; ESRerythrocyte sedimentation rate; CRP-C-reactive protein

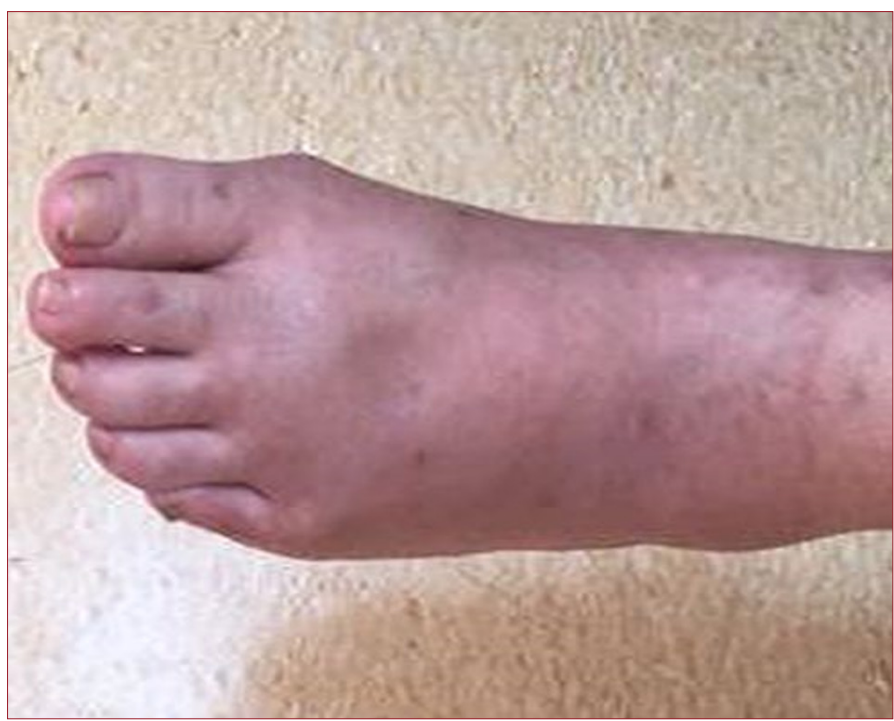

Figure 2. Clinical photograph of the patient showing pitting edema over the dorsum of the foot

Table 1. Demographic and clinical characteristics of RS3PE disease patients

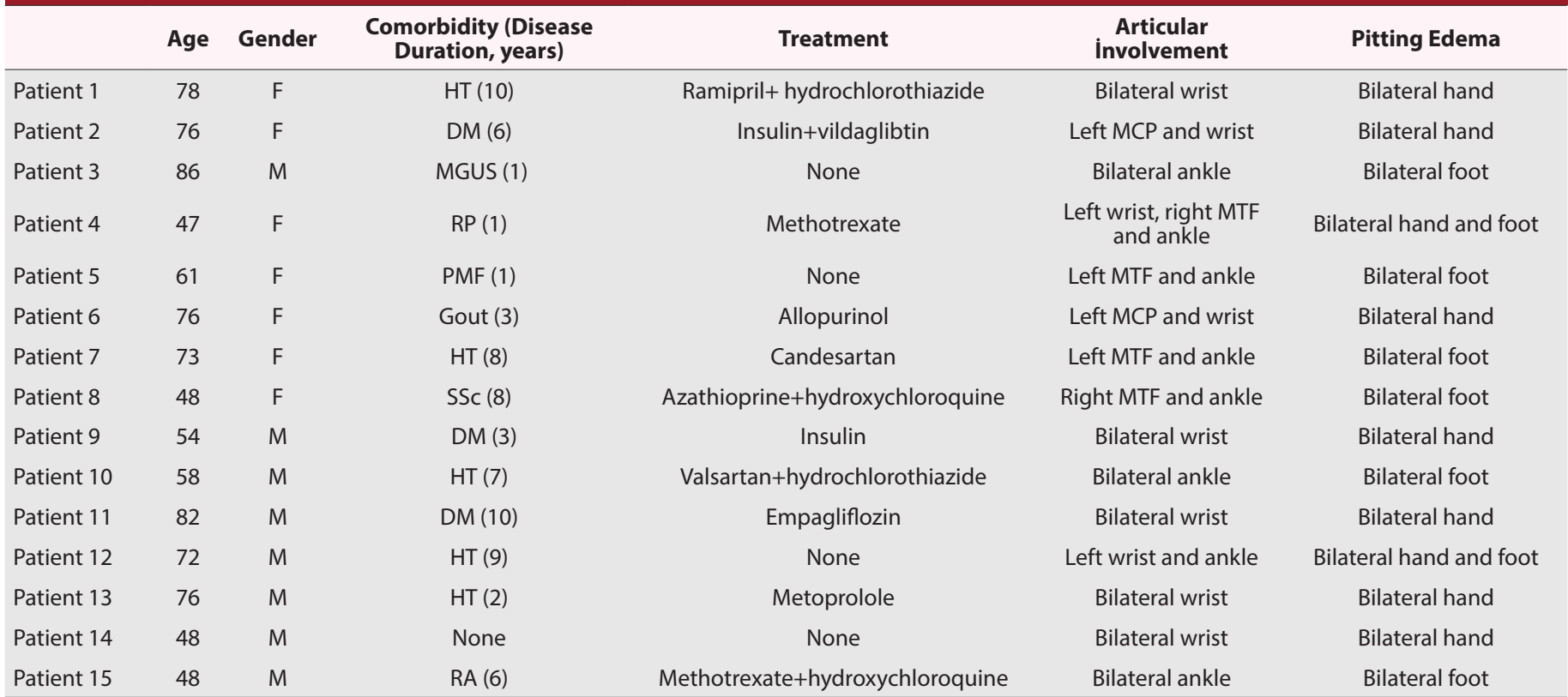

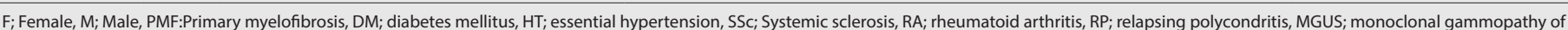
undetermined significance, MCP: metacarpophalangeal, MTP; metatarsophalangeal 


\section{DISCUSSION}

RS3PE cases are mostly idiopathic. Albeit etiopathogenesis remains to be completely elucidated, it has been stated that genetic susceptibility, infections, drugs, rheumatological and autoimmune diseases play a role. ${ }^{[5]}$ The role of vascular endothelium growth factor (VEGF), which contributes to subcutaneous edema in extremities and polysynovitis by increasing vascular permeability, has been demonstrated recently. It is assumed that neoplasia, other drugs, and medical conditions may trigger VEGF production and other molecules, stimulating vascular permeability in RS3PE syndrome, resulting in pitting edema and polyarthritis/ polysynovitis in extremities. Studies on the pathogenesis of RS3PE are restricted to Japanese reports, and sample magnitudes are small. Considering that RS3PE is a heterogeneous syndrome and is associated with malignities in a substantial number of cases, further investigation of different potential mechanisms is needed in RS3PE patients, particularly in the ones with neoplasia. Studies including few patients demonstrated that high interleukin 6 (IL-6) levels in serum and synovial fluid reveal the disease's inflammatory characteristics. ${ }^{[6]}$ Even though it is known as a disease of the elderly population, it may occur in younger age groups. ${ }^{[7]}$ In the present study, 5 out of 15 patients were under the age of 60.

Pitting edema is the most specific property. Edema of both hand and foot have been reported. The most commonly affected joints are the wrist, ankle, metacarpophalangeal, and proximal interphalangeal joints. It is thought that it does not lead to permanent damage in joints, but mild residual joint limitations may occur. Until Pariser and Canosa reported two unilateral RS3PE cases, it was regarded as a symmetrical entity ${ }^{[8]}$ Then, in the case series of Finnell and Cuesta, asymmetrical involvement in lower extremities was reported. ${ }^{[9]}$ In our series, the involved joints were similar to those reported in the literature, but cases with unilateral asymmetrical involvement made up the majority. Laboratory parameters include high levels of acute-phase reactants (ESR, CRP), indicating an underlying inflammatory process. RF and anti-CCP are typically negative, and the ANA test has rarely been reported to be positive. Radiologically, there are no erosions. ${ }^{[10]}$ Tenosynovitis has been demonstrated with the imaging of extremities using ultrasonography and /magnetic resonance imaging. In our cases, laboratory and radiological findings were consistent with those reported in the literature. ${ }^{[1]}$ Although diagnostic criteria of RS3PE are clear, due to accompanying systemic complaints in geriatric age groups and probable concurrence with other diseases, the differential diagnosis may become challenging. In the differential diagnosis of RS3PE, polymyalgia rheumatica (PMR) and late-onset RA are essential as they affect similar age groups and have some common characteristics. ${ }^{[12]}$ Although it was originally defined as a subgroup of RA, it is distinct from RA in that RA leads to erosive changes and marked morning stiffness, rheumatic nodules are present, is associated with HLA-DRB1 alleles, is RF positive, and requires long terms, disease modifying agents. In PMR, shoulder hip girdle pain is predominant in the clinical picture, complaints are associated with systemic symptoms that emerge in the longer term, and high dose steroids are required, which are differentiating characteristics. The occurrence at advanced ages, being seronegative, high sedimentation levels, and dramatic response to steroids cause the syndrome to be confused with PMR. However, the preponderance of male patients and pitting edema are not expected in PMR. Other rheumatological diseases, hypothyroidism, congestive heart failure, nephrotic syndrome, venous failure, lymphedema, cellulitis, osteomyelitis, and tenosynovitis should be considered in the differential diagnosis. Particularly in longstanding dialysis patients, extracellular fluid accumulation in hands and feet and development of amyloid arthropathy may produce a clinical picture resembling RS3PE syndrome. The diagnosis was made following differential diagnosis established with the clinical, physical examination, laboratory, and radiological findings in the present study. However, it should be kept in mind that differential diagnosis may be quite challenging.

A study ${ }^{13]}$ evaluated 331 RS3PE cases reported by 121 studies, concurrent rheumatological conditions were reported in 22 cases (6.65\%), and malignity in 54 cases. (16.31\%). The aforementioned data support the idea that RS3PE is a syndrome, which potentially has heterogeneous etiology. Various rheumatismal diseases have been reported to be concurrent with RS3PE'. They include systemic lupus erythematosus, gout, Sjögren syndrome, polyarteritis nodosa, ankylosing spondylitis, sarcoidosis, amyloidosis, recurrent polychondritis, and bronchiolitis obliterans organizing pneumonia. RS3PE may also be associated with infections such as bacillus Calmette-Guerin (BCG), parvovirus, and Streptobacillus moniliformis. ${ }^{[14,15]}$ Özşahin et al. reported the occurrence of unilateral RS3PE in a patient with rheumatoid arthritis who received DMARD treatment but later discontinued it as symptoms could not be controlled. ${ }^{[7]}$ RS3PE developed three years after the discontinuation of drugs. Another case was controlled well with DMARDs, and similar to our case, RS3PE developed during treatment. This case indicates that RS3PE may be considered a different clinical entity since it occurred regularly in a patient receiving DMARD.

Pittau et al.. ${ }^{[16]}$ described a case of SLE with pitting edema in distal lower limbs. In 1999, Günaydın et al. ${ }^{[17]}$ reported two cases of SLE with unproven pathogenesis and lower extremity pitting edema who responded to steroids rapidly. In 2008, Alpigiani et al. reported a case of pediatric SLE whose symmetrical pitting edema in hands and feet improved. ${ }^{[18]}$ In a literature review, 7 RS3PE cases associated with SLE were reported. ${ }^{[17]}$ Young Mi Choi et al. and Fietta $\mathrm{P}$ et al. reported the coexistence of Sjögren disease and RS3PE in their cases, respectively. ${ }^{[20]}$ In Scleroderma, as dermatological findings, usually bilateral sclerodactyly and nonpitting edema are observed. Edema is the earliest finding of scleroderma. In our 
scleroderma cases, whose disease duration was eight years, bilateral foot pitting edema and asymmetrical ankle arthritis were observed. This coexistence was not described before in the literature. It is a rare concurrence and may easily be confused with other diagnoses, which renders it significant.

In one of our cases, dyspnea, hoarseness, arthritis in metatarsophalangeal joints, left wrist and right ankle, and pitting edema on hand and foot dorsum were present. Nasal, auricular chondritis and bronchial involvement were detected, and the patient was diagnosed with relapsing polychondritis (RP) and RS3PE. In the literature, a 72-yearold male case with concurrent RS3PE and MDS, which were diagnosed simultaneously, has been reported. ${ }^{[21]}$ A few months later patient displayed a clinical and pathological picture consistent with RP. Although the relation between RP and RS3PE and MDS is well known, RS3PE cases developing after RP have not been reported. ${ }^{[22]}$ In our case, only RP and RS3PE concurrence were present without any hematological malignity. Also, unlike the other case, RS3PE developed after $\mathrm{RP}$ findings in a young female patient

RS3PE syndrome, caused by crystal arthritis, in particular gout, is quite rare. In reported cases, patients were previously diagnosed with gout. However, they did not continue treatment and had recurrent gout attacks. In our case, RS3PE developed under treatment. Even though RS3PE caused by gout is very seldom, clinicians should take gout-associated RS3PE syndrome into account when diagnosing symmetrical inflammatory diseases since gout/hyperuricemia is a widespread disease irrespective of race. Palazzi et al. reported that gout RS3PE syndrome was successfully treated with ten days of meloxicam cure. ${ }^{[23]}$ Sugisaki and Hirose reported another gout-associated RS3PE syndrome case in which NSAID treatment exerted no therapeutic effect and was finally successfully treated with low-dose oral prednisolone. ${ }^{[24]}$

Recent studies have demonstrated the association of RS3PE with antidiabetic drugs such as insulin and dipeptidyl peptidase-4 (DPP-4) inhibitör Yamauchi et al. reported two Japanese cases of RS3PE syndrome, which arose after the onset of DPP4 treatment. ${ }^{[25,26]}$ Yokota and lgaki reported a case of polyarthritis developing after the initiation of sitagliptin, diagnosed with RA, and whose arthritis improved after the withdrawal of sitagliptin. ${ }^{[27]}$ Insulin directly increases VEGF-A mRNA and protein expression in various tissues, including cardiac myocytes and renal podocytes. Cases associated with insulin treatment have been reported. ${ }^{[28]}$ However, recently K. Oyama et al. Have reported four cases of RS3PE, who have type 2 diabetes mellitus or impaired glucose tolerance without DPP-4 inhibitor drug. ${ }^{[29]}$ In our case series, three patients had DM. Two were on insulin, while one received empagliflozin, which was instituted six months before the appearance of arthritis. No relation between syndrome and empagliflozin has been reported in previous literature. Further studies are required in order to corroborate the relation between DM and its treatment and RS3PE.
Both cancer and benign masses have been reported since 1985 in association with RS3PE. ${ }^{[30]}$ Malignities reported in this syndrome involve both hematological malignities and solid tumors. The relation between RS3PE and neoplasms may suggest that it may be a paraneoplastic syndrome. Among solid tumors, a more common relation was reported with prostate, colon, and stomach adenocarcinomas. There are other cases of RS3PE associated with the ovary, endometrial carcinoma, bladder, lung, breast, and cryptogenic hepatocellular carcinoma. It has also been reported that some hematological malignities such as chronic lymphocytic leukemia, $\mathrm{T}$ cell lymphoma, angioimmunoblastic $\mathrm{T}$ cell leukemia, B cell non-Hodgkin lymphoma, and myelodysplastic syndrome are associated with RS3PE syndrome. It is thought that inflammatory cytokines released from tumor cells play a role in its pathogenesis. The best management of paraneoplastic RS3PE syndrome is the treatment of malignant processes. ${ }^{[31]}$ Malignity may develop before, during, or after the appearance of the syndrome. Therefore, in patients diagnosed with RS3PE syndrome, the paraneoplastic syndrome should be ruled out, and patients should be monitored for a long time if necessary for life long due to the probability of malignity. Yao et al. reviewed the literature on RS3PE and proposed that the rate of malignity associated with RS3PE may be as high as $54 \%$.

Nevertheless, there is no large case series or population survey on RS3PE, and the actual prevalence of neoplasms in this syndrome is unknown. More severe disease with systemic symptoms and weak response to treatment increases the probability that this clinical picture may represent a neoplastic process. Therefore, cancer screening appropriate to the age of the patient is recommended. No solid malignity was found in our case series, but two hematological malignities were identified. i.e., one case of primary myelofibrosis and one case of MGUS, diagnosed after screening made following the diagnosis of RS3PE. Recurrence occurred in two patients after the dose of steroid was decreased. The Hematology department followed them. A case associated with multiple myeloma has been reported in the literature, but no association with myelofibrosis has been reported.

To treat RS3PE patients with no underlying disease, steroids at low doses should be used for 18 months. Most patients respond well to steroids, and symptomatic improvement is observed within 24-72 hours of glucocorticoid onset. Disease-Modifying Anti Rheumatismal Drugs play a minimal role. Generally, RS3PE cases without any accompanying neoplasm have a favorable prognosis. This remission is usually permanent.

Conversely, in the presence of an underlying malignity, RS3PE has an inadequate response to treatment, and primary treatment of underlying malignity is necessary. In patients with $\mathrm{RS} 3 \mathrm{PE}$, resistance to low-dose corticosteroid treatment and the presence of concurrent systemic symptoms should warn the clinicians about the presence of probable malignity. ${ }^{[32]}$ Therefore, increasing awareness of associated clinical characteristics and possible comorbid conditions is of significance. 
Limitations of the study: The study's main limitation is that it was carried out at a single center with few cases.

\section{CONCLUSION}

The rare occurrence of this syndrome leads clinicians to miss it commonly, which gives rise to the administration of unnecessary long-term treatments. Another essential point that clinicians should be borne in mind is that RS3PE may be encountered as paraneoplastic syndrome in various hematological and solid malignities and may also be associated with various autoimmune and rheumatological diseases and drugs. The relation between RS3PE and four new conditions, i.e., scleroderma and relapsing polychondritis, monoclonal gammopathy of unknown significance, and primary myelofibrosis The present study aimed to discuss cases diagnosed with RS3PE, review the literature on this issue, and increase awareness of this entity among clinicians by describing its characteristics.

\section{ETHICAL DECLARATIONS}

Ethics Committee Approval: Approval for the study was obtained from the ethics committee with the decision dated 22.04.2020 and numbered. 2020/181.

Informed Consent: All patients signed the free and informed consent form.

\section{Referee Evaluation Process: Externally peer-reviewed.}

Conflict of Interest Statement: The authors have no conflicts of interest to declare.

Financial Disclosure: The authors declared that this study has received no financial support.

Author Contributions: All of the authors declare that they have all participated in the design, execution, and analysis of the paper, and that they have approved the final version.

Acknowledgments: We deeply acknowledge our patient for the consent to publish this research for teaching medical professionals to help their patients better

\section{REFERENCES}

1. McCarty DJ, O'Duffy JD, Pearson L, Hunter JB. Remitting seronegative symmetrical synovitis with pitting edema. RS3PE syndrome. JAMA 1983;254:2763-7

2. Lakhmalla M, Dahiya DS, Kichloo A, Fatima T, Edigin E, Wani F. Remitting seronegative symmetrical synovitis with pitting edema:a review. J Investig Med 2021;69(1):86-90.

3. Varshney AN, Kumar N, Tiwari A, et al. Unilateral RS3PE in a Patient of Seronegative Rheumatoid Arthritis. Case Rep Rheumatol. 2013;2013:923797.

4. Olivo D, D'Amore M, Lacava R, et al. Benign edematous polysynovitis in the elderly (RS3PE syndrome). Clin Exp Rheumatol. 1994;12(6):669-73.

5. KenzakaT.The Relationship between Remitting Seronegative Symmetrical Synovitis with Pitting Edema and Vascular Endothelial Growth Factor and Matrix Metalloproteinase 3. Intern Med 2020;59(8):1021-2

6. Oide T, Ohara S, Oguchi K, et al. Remitting seronegative symmetrical synovitis with pitting edema (RS3PE) syndrome in Nagano, Japan:clinical, radiological, and cytokine studies of 13 patients. Clin Exp Rheumatol 2004;22(1):91-8.
7. Özşahin M, Ataoğlu S, Turan H. Unilateral RS3PE with young-onset rheumatoid arthritis. Seminars in Arthritis and Rheumatism 2011;40(4):e1.

8. Pariser KM, Canosa JJ. Remitting seronegative symmetrical synovitis with pitting edema-two cases of RS3PE syndrome. J Rheumatol $1991 ; 18(8): 1260-2$

9. Finnell JA, Cuesta IA. Remitting seronegative symmetrical synovitis with pitting edema (RS3PE) syndrome:a review of the literature and a report of three cases. J Foot Ankle Surg 2000;39:189-93.

10. Joseph AD, Kumanan T, Aravinthan N, Suganthan N. An unusual case of remitting seronegative symmetrical synovitis with pitting edema:Case report and literature review. SAGE Open Med Case Rep 2020;8:2050313X20910920.

11. Klauser A, Frauscher F, Halpern EJ, et al. Remitting seronegative symmetrical synovitis with pitting edema of the hands:ultrasound, color doppler ultrasound, and magnetic resonance imaging findings. Arthritis Rheum 2005;53(2):226-33.

12. Eguia HA, Parodi Garcia JF, Ramas Diez C, Eguia AEA. Remitting seronegative symmetrical synovitis with pitting edema (RS3PE) case presentation and comparison with other polyarthritides affecting older people. Age Ageing 2017;46(2):333-334.

13. Karmacharya $P$, Donato $A A$, Aryal MR, et al. RS3PE revisited:a systematic review and meta-analysis of 331 cases. Clin Exp Rheumatol 2016;34(3):40415.

14. Paira S, Graf C, Roverano S, Rossini J. Remitting seronegative symmetrical synovitis with pitting edema:a study of 12 cases. Clin Rheumatol 2002;21(2):146-9.

15. Varshney AN, Singh NK. Syndrome of remitting seronegative symmetrical synovitis with pitting edema:a case series. J Postgrad Med 2015;61:38-41.

16. Pittau E, Passiu G, Mathieu A. Remitting asymmetrical pitting edema in systemic lupus erythematosus:Two cases studied with magnetic resonance imaging. Joint Bone Spine 2000;67:544-549

17. Günaydin, I, Daikeler T, Mohren M. Lower limb pitting edema in systemic lupus erythematosus. Rheumatol Int 1999;18:159-60

18. Alpigiani MG, Giampietri L, Emmanuele V, Salvati $P$, Valle M, Lorini $R$. Remitting symmetrical pitting edema of hands and feet at onset of pediatric systemic lupus erythematosus:a case report. Clin Exp Rheumatol 2008;26(6):1166.

19. Hegazi MO, Saleh F, Al Rashidi A, Yaktien MM. Synovitis with pitting edema as the presenting manifestation of systemic lupus erythematosus. Lupus 2014;23(10):1069-72.

20. 20.Choi YM, Sheen DH, Lee YJ, Lee EB, Song YW. Sjogren's syndrome presenting as remitting seronegative symmetric synovitis with pitting edema (RS3PE). J Korean Med Sci 2003;18(4):606-8.

21. Manganelli P, Delsante G, Bianchi G, Fietta P, Quaini F. Remitting seronegative symmetrical synovitis with pitting edema in a patient with myelodysplastic syndrome and relapsing polychondritis. Clin Rheumatol 2001;20(2):132-5.

22. Matsunaga $\mathrm{T}$, Izumi $\mathrm{Y}$, Iwanaga $\mathrm{N}$, et al. Myelodysplastic syndrome precedes the onset of remitting seronegative symmetrical synovitis with pitting edema (RS3PE) syndrome. Tohoku J Exp Med 2015;235(1):47-52.

23. Palazzi C, Olivieri I, D'Amico E, Pace-Palitti V, Petricca A. Symmetrical pitting edema resembling RS3PE in gout. Clin Rheumatol 2003;22(6):5067.

24. Sugisaki K, Hirose T. Remitting seronegative symmetrical synovitis with pitting edema (RS3PE) syndrome following spontaneous rupture of a gouty tophus. Mod Rheumatol 2008;18:630-3.

25. Horai Y, Origuchi T, Iwanaga N, et al. Clinical analysis of pre-existing diabetes mellitus and dipeptidyl peptidase-4 inhibitors in patients with remitting seronegative symmetrical synovitis and pitting edema syndrome. Mod Rheumatol 2020;30(4):703-7.

26. Yamauchi K, Sato Y, Yamashita K, et al. RS3PE in association with dipeptidy peptidase-4 inhibitor:report of two cases. Diabetes Care 2012;35(2):e7.

27. Yokota K, Igaki N. Sitagliptin (DPP-4 inhibitor)-induced rheumatoid arthritis in type 2 diabetes mellitus:a case report. Intern Med 2012;51(15):2041-4.

28. Mainali NR, Schmidt TR, Alweis R, George DL. Novel Development of Remitting Seronegative Symmetrical Synovitis with Pitting Edema (RS3PE) Syndrome due to Insulin Therapy. Am J Case Rep 2014;15:119-22. 
29. Oyama K, Taniguchi Jl, Goto R, Matsui K. Remitting seronegative symmetrical synovitis with pitting edema syndrome in individuals with type 2 diabetes mellitus or impaired glucose tolerance. Diabetes Res Clin Pract 2015;110(1):e5-e8.

30. Manzo C, Natale M. Polymyalgia Rheumatica in Association with Remitting Seronegative Synovitis with Pitting Edema:a Neoplastic Warning. Can Geriatr J 2017;20(2):94-6.

31. Tunc SE, Arslan C, Ayvacioglu NB, Sahin M, Akkus S, Yorgancigil H. Paraneoplastic remitting seronegative symmetrical synovitis with pitting edema (RS3PE syndrome):a report of two cases and review of the literature. Rheumatol Int 2004;24(4):234-7.

32. Nojima $Y$, Ihara $M$, Adachi $H$, Kurimoto $T$, Nanto S. Impact of low-dose prednisolone on refractory pitting edema manifesting remitting seronegative symmetrical synovitis with pitting edema syndrome. J Cardiol Cases 2016;14(4):119-22. 